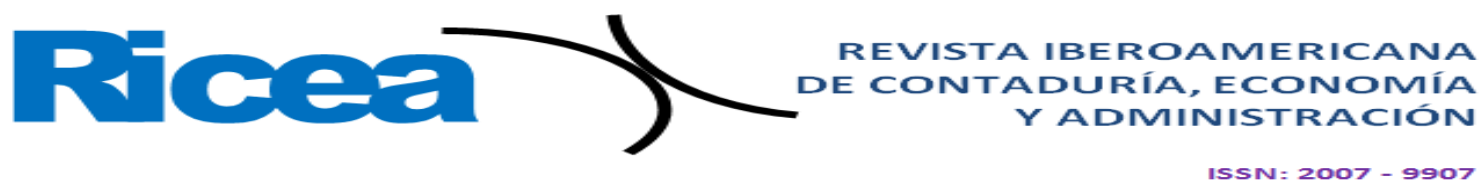

https://doi.org/10.23913/ricea.v8i16.141

Artículos Científicos

\title{
Basilea III en México y la relación entre la regulación financiera y el financiamiento
}

\author{
Basel III in Mexico and the Relationship Between Financial Regulation and \\ Financing
}

\section{Basileia III no México e a relação entre regulamentação financeira e financiamento}

\author{
Cecilia Medrano Martínez ${ }^{1}$ \\ Universidad del Distrito Federal, Campus Santa María, México \\ cecy3.0@hotmail.com \\ https://orcid.org/0000-0002-5548-4247
}

\section{Resumen}

La regulación financiera y el financiamiento en México siempre han estado relacionados con el sector empresarial. Con la crisis financiera mundial en al año 2008 cambiaron las medidas acordadas internacionalmente para regular y supervisar la banca. En esta investigación se realiza un análisis del acuerdo de Basilea III y cómo se desarrolla en el esquema regulatorio hacia el crédito. El objetivo es demostrar las principales variables entre el análisis de la regulación financiera y dicho acuerdo en el sector de las micro, pequeñas y medianas empresas (mipymes). Esto a través de un método deductivo y una metodología aplicada cualitativa. Como parte de los resultados se encontró que si bien no hay una sola razón por la que el estrato empresarial no solicita un crédito a la banca, mayoritariamente se debe a que las tasas de interés son elevadas y no cuenta con la suficiente solvencia para la adquisición de uno y pagar la deuda en determinado plazo. Finalmente, aunque se reconoce que existen apoyos para brindar un crédito o financiamiento a las mipymes en México, aún hay áreas de

\footnotetext{
${ }^{1}$ Postdoctora. Cecilia Medrano Martínez.
} 
oportunidad y temas que se deben desarrollar siguiendo las recomendaciones del acuerdo de Basilea III.

Palabras clave: Basilea III, crisis, esquema regulatorio, financiamiento, sector empresarial.

\section{Abstract}

Financial regulation and financing in Mexico have always been related to the business sector. With the global financial crisis in 2008, the internationally agreed measures to regulate and supervise banks were changed. In this investigation, an analysis of the Basel III agreement and how it is developed in the regulatory scheme towards credit is carried out. The aim is to demonstrate the main variables between the analysis of financial regulation and the Basel III agreement in the sector of micro, small and medium enterprises (MSMEs). This through a deductive method and a qualitative applied methodology. Among the results achieved was found that the business stratum does not request a credit from the bank for different reasons, but mostly because interest rates are high and does not have sufficient solvency to acquire one and pay the debt in a certain period. Finally, although it is recognized that there are supports to provide credit or financing to MSMEs in Mexico, there are still areas of opportunity and issues that should be developed following the recommendations of the Basel III agreement.

Keywords: Basel III, crisis, regulatory, financing, business sector scheme.

\section{Resumo}

A regulamentação e o financiamento financeiros no México sempre foram relacionados ao setor comercial. Com a crise financeira global em 2008, as medidas acordadas internacionalmente para regular e supervisionar o setor bancário mudaram. Nesta investigação, é realizada uma análise do acordo de Basileia III e como ele é desenvolvido no esquema regulatório para o crédito. O objetivo é demonstrar as principais variáveis entre a análise da regulamentação financeira e o referido acordo no setor de micro, pequenas e médias empresas (MPME). Isso através de um método dedutivo e uma metodologia aplicada qualitativa. Como parte dos resultados, constatou-se que, embora não exista uma única razão pela qual o estrato corporativo não solicite crédito ao banco, é principalmente porque as taxas 
de juros são altas e não possuem solvência suficiente para a aquisição. de um e pagar a dívida em um determinado prazo. Finalmente, embora se reconheça que existem apoios para fornecer crédito ou financiamento às MPME no México, ainda existem áreas de oportunidades e questões que devem ser desenvolvidas seguindo as recomendações do acordo de Basileia III.

Palavras-chave: Basileia III, crise, esquema regulatório, financiamento, setor empresarial.

Fecha Recepción: Octubre 2018 Fecha Aceptación: Junio 2019

\section{Introducción}

Esta investigación tiene como propósito analizar el papel del Comité de Basilea III en los mercados financieros en México, pues de ahí parten las principales variables para la obtención o no de un crédito por parte de las micro, pequeñas y medianas empresas (mipymes). Por ello, el Banco de México (Banxico) debe estar ajustado a las políticas y a los estándares internacionales que el mercado financiero demanda.

Basilea III es un marco de medidas internacionales acordadas para reforzar, regular y supervisar el riesgo de los bancos. Tiene la misión de encargarse específicamente de temas económicos financieros a nivel internacional. Mientras que dentro del marco regulador de la economía mexicana está el Banxico, entidad que, al igual que el Comité de Basilea, se orienta a las prácticas sanas del sistema de pagos del sistema financiero mexicano (SFM), a la disciplina del mercado, al apego de las buenas prácticas bancarias y a la transparencia financiera, por citar algunas.

La regulación internacional bancaria ha sufrido desbalances a lo largo de la historia de cada país. Cabe recordar el quebranto de los bancos de Estados Unidos en 2008 y la crisis del año 2011 en Europa, ambos eventos con repercusiones en México. En ese sentido, si un desbalance político, social y económico afecta a un país o una región de ese peso obviamente otras naciones se verán afectadas.

Ahora bien, la regulación debe existir en México y en cualquier otra economía por temas específicos de transparencia en los procesos bancarios. La regulación en la banca de desarrollo y múltiple está supervisada por el banco central del Estado mexicano, a su vez supervisado por Basilea III, y es que de no sujetarse a los lineamientos descritos con 
anterioridad difícilmente se podrían resolver y llegar a diferentes acuerdos con coordinación y lucidez.

Esta investigación emprende un análisis de la regulación bancaria en México y por qué es importante entender el contexto del acuerdo de Basilea III en el momento en que alguna mipyme solicite un crédito o financiamiento a la banca de desarrollo y banca central.

El presente artículo aborda, en primer lugar, la regulación bancaria y el sentido que ofrece en la apertura de un crédito o financiamiento al estrato empresarial; luego se describe de manera gráfica el crecimiento de México y otros países, el crecimiento y el apoyo que les da el Gobierno. Posteriormente, el método, la propuesta y los resultados fundamentados en una discusión. Como corresponde, las conclusiones cierran este texto.

\section{La regulación bancaria en México y su sentido para el crédito}

La Asociación Mexicana de Asesores Independientes de Inversiones [Amaii] (2017) declara que el SFM es un conjunto de organismos que administra y canaliza la inversión, el ahorro dentro del marco legal que corresponde al territorio nacional, mediante la captación de recursos financieros nacionales y extranjeros para integrar una negociación a través de la sana regulación del país.

El SFM está compuesto por una enorme serie de entidades e intermediarios financieros, quienes, relacionados de manera directa e indirecta con independientes, empresas y diferentes sectores, tal vez los más conocidos provengan de la entidad financiera, ayudan de forma inmediata y evasiva al crecimiento, competitividad y sustentabilidad de la nación mexicana.

Algunas de las actividades que ejecuta el SFM es apoyar a terceros mediante la adquisición de créditos, o bien, al rendimiento de sus recursos. Es decir, la función es de intermediario tanto a los que necesitan como a los que tienen dinero, pues con la sociedad globalizada de hoy en día es complicado que un solo banco o institución regule las transacciones diarias que en el mercado se suscitan. Por ello se considera más efectivo que los movimientos los haga un sistema financiero con miras a facilitar y regular las tareas mencionadas. 


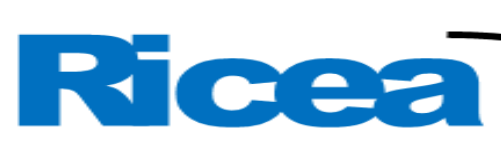

REVISTA IBEROAMERICANA DE CONTADURÍA, ECONOMÍA

Y ADMINISTRACIÓN

ISSN $=2007-9907$

Existen diversas teorías para la adquisición de un crédito o financiamiento para las mipymes en México, pero los principales problemas a los que estas se enfrentan son el pago del crédito, bajos salarios a los empleados, planeación y trámites burocráticos. De tal forma que no se han logrado aumentar los volúmenes de consecución de crédito hacia este sector.

De acuerdo con Gascón (11 de mayo de 2015), algunos de los diversos problemas para las limitaciones de la obtención de un crédito hacia las mipymes es la falta de responsabilidad presente en algunas de las pequeñas y medianas empresas en México, además de computar con reducido personal y la carencia de un plan de negocios. En ese sentido, Camacho (24 de agosto de 2010) menciona que este sector parte de un vulnerable y frágil sistema financiero y de oportunidad, pues el financiamiento a las pequeñas es de $5 \%$ o menos, $10 \%$ y $20 \%$ entre medianas y grandes respectivamente.

La esperanza de vida promedio de una mipyme es de 7.7 años, según el Instituto Nacional de Estadística y Geografía [Inegi] (2016). La edad promedio para cada empresa que se instituye en el país no llega lamentablemente a un período prolongado y en su mayoría desaparecen del sector o sus recursos se encuentran obsoletas.

En su portal, Banxico (2015) indica que la oferta de créditos para las mipymes impulsa la competencia entre los agentes de crédito de la banca múltiple y la banca de desarrollo a fin de ofrecer mejores contratos de financiamiento y crédito hacia estas organizaciones, y que estos, los contratos, sean acordes a sus expectativas para generar un valor a través de la vida del mismo de acuerdo.

A pesar de contar con un apoyo financiero y que en muchos casos no es el adecuado para las mipymes, también deben obedecer ciertas variables internas y externas en materia económica, tal como lo comenta Beltrán (2006), y que de ellas dependan o consten la construcción de un plan estratégico, la implantación de metodologías adecuadas, las capacidades y habilidades que tiene la empresa, además de la construcción de un plan de negocios, sobre todo en las micro y pequeñas empresas, pues en términos operativos es la edificación de la iniciativa empresarial.

De no ser así, además de la negación de la consecución del crédito por parte de la banca hacia este sector, también se ven afectadas las políticas de la empresa, e incluso se ven obligadas a descartar exportaciones hacia nuevos mercados y recurren a la falta de pago a los proveedores. Así, pues, los empresarios, por no contar en términos de decisión y de ejecución 
unos planes de acción, se ven sumamente afectados, pues el nivel de endeudamiento promedio es de $70 \%$ en un periodo no mayor a un año.

El control de las micro empresas comerciales en el país es excesivo, ya que en la mayoría destacan los negocios familiares, en donde se representa una aproximación de diez empleados. Después de lo cual existen diferentes teorías por las cuales las empresas no alcanzan su crecimiento y expansión, y uno de los principales problemas que se pudo observar en la investigación es el financiamiento para la misma.

Para aproximar una cifra en términos de apoyo hacia este sector, Nacional Financiera [Nafin] (2016) anunció el financiamiento a los que tuvieron acceso las empresas a través de Banco Santander, y el saldo promedio fue casi de 120000000000 de pesos en beneficio de más de 100000 empresas. Sin embargo, en ese mismo año, únicamente el acceso al crédito lo obtuvieron empresas existentes en la cartera del banco. Sin duda esa es otra dificultad para las mipymes que se vieron en un escenario de oportunidad y crecimiento, además de la exhaustiva investigación crediticia a la que la empresa fue sujeta para la obtención del apoyo.

Por otra parte, se deduce con este ejemplo que es difícil sobrevivir al rechazo de la banca múltiple y privada para la adquisición de un crédito o financiamiento, pues, además de llevar variables internas en excelente estado, también se debe tomar en cuenta otros factores para las empresas que buscan un crecimiento, o tal vez una expansión: una apertura a nuevos mercados, el pago a proveedores, el pago a nómina o el comienzo a las exportaciones, solo por citar de las más importantes. Es difícil, una vez más, si no se cuenta también con un extraordinario historial crediticio.

¿Cómo se va a lograr contar con un crédito si la empresa es nueva, o quizá si la empresa no cuenta con los suficientes recursos, si su gestión es obsoleta, o peor aún si no le brinda confianza en el mercado financiero interno del país? El financiamiento en México por parte del Gobierno (banca de desarrollo) e instituciones financieras (banca múltiple) ha generado mayor incertidumbre y desconfianza hacia los empresarios, por razones como el nivel de inseguridad, la paridad con el dólar, las tasas de interés, los cambios políticos, sociales y económicos internacionalmente que actualmente se están viviendo, así como los altos costos por la adquisición de un crédito, lo que ha denotado la disminución de los mismos considerablemente. 
El Sistema Único de Gestión Empresarial [SUGE] (2016), dependencia del Gobierno del Estado de México, no está de acuerdo con la administración ni con los procesos internos manejados y argumenta que se aprovechan de la situación de la mipymes, pues acotan en el tema de apertura, de ampliación y organización para limitar el crecimiento del sector empresarial.

Algunos de los requisitos para ser sujeto a crédito por parte de la banca de desarrollo como empresa son similares a los de la banca múltiple, ya que corre el riesgo a la capacidad de pago de la empresa, a la estimación de la rentabilidad y factibilidad del proyecto, y que en muchas ocasiones también libera un ambiente de estrés y tensión para los empresarios en el tiempo de respuesta, que no necesariamente es positivo.

\section{La mipyme y la banca, ;falta de alianzas?}

El Instituto Nacional del Emprendedor [Inadem] (2016) desarrolló un programa para fomentar la productividad al sector empresarial mediante alianzas y estrategias definidas. A dicho proyecto se le destinaron 140000000 de pesos, de los cuales $99 \%$ del capital se utilizó pero solo a pequeñas, medianas y grandes empresas.

Entonces, ¿qué sucede con las microempresas?, ¿quién las apoya?, ¿bajo qué lineamientos les declinan el crédito?, ¿por qué no son sujetas a un crédito o financiamiento por parte de la banca? Cabe resaltar que tan solo en 2015 conformaban $97.6 \%$ del estrato empresarial, con $75 \%$ de personal ocupado.

Y claro, esto sin contar los estados que se vieron beneficiados: Estado de México, Coahuila de Zaragoza, Guanajuato, Ciudad de México, Jalisco, Morelos, Sinaloa, Hidalgo, Veracruz, Tamaulipas, Puebla, Colima, Oaxaca y Nayarit. Lo cual abre el camino a la siguiente pregunta: ¿Qué pasa con el resto del país?

Pero estos problemas tienen una raíz, la cual ha sido, en términos económicos, favorables, y en términos de crecimiento empresarial, un golpe difícil. Puesto que, aunque en 2015 el Comité de Basilea III le dio la calificación “C” a México, la cual implica el cumplimiento de los requerimientos que el acuerdo demanda, también se deben plantear los problemas que ha generado la política. 


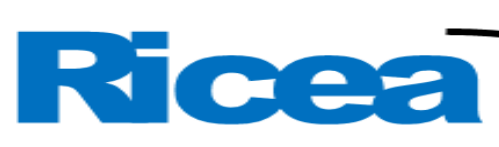

REVISTA IBEROAMERICANA
DECONTADURIA, ECONOMIIA
Y ADMINISTRACIÓN

ISSN : $2007-9907$

La política pública en el país, que es quien toma las decisiones financieras en México, pues, se contrapone al aprovechamiento de las millonarias ganancias por las altas tasas de interés cobradas por la banca en términos de crédito y financiamiento que cobijan los políticos. Más aún, la vida del crédito en México, de acuerdo con lo descrito, es obsoleta y no cumple con las expectativas por parte del estrato empresarial, pues no solo es el tema de la regulación, también es el tema de la apertura de nuevas fuentes de financiamiento y a la falta de visión que el empresario debe representar en su mipyme.

De acuerdo con el reporte del Inegi (2015a), las principales características de las microempresas son la siguiente: tienen $75 \%$ del personal ocupado de la economía y $14.7 \%$ cuenta con educación superior. Con base en lo descrito se puede deducir que casi $70 \%$ de la capacidad que tienen la empresa detiene su productividad eficaz y eficiente completamente por la falta de libertad económica hacia su expansión, pues en los años de operación se preocupa más en estar pagando altos intereses por la adquisición de un crédito en lugar de invertirlo en su empresa, o en la falta de dominio del personal, pues con los bajos salarios solo $11 \%$ capacita a su planta laboral — claro está que es por la fuga de personal y constante rotación del mismo. Esto solo por justificar algunos de los diferentes problemas descritos que tiene la microempresa.

Mientras que en ese mismo año pero de otro mes el mismo Inegi (2015a) describió las características de las pequeñas empresas: $51 \%$ del personal ocupado tiene educación media superior. Las pequeñas empresas siguen en una categoría de poco crecimiento, pues su nivel de productividad es de $45 \%$, es decir, poco más de la mitad se concentra en la fuga de empleados. Las medianas empresas son las que cuentan con mayores oportunidades de crecimiento, ya que 74 de cada 100 empresas imparten capacitación y $43.6 \%$ de las empresas soluciona los problemas en el proceso de producción e instrumentan la mejora continua. Con respecto a lo anterior, aquí sí las oportunidades de crecimiento son más favorables que en los demás sectores, pues su índice de crecimiento con base en la adquisición de un crédito es de $80 \%$, es decir, que más de la mitad tiene un excelente nivel de aprobación por parte de la banca. 


\section{El escenario en México para las mipymes}

El problema de los financiamientos y créditos no es tan catastrófico en las medianas empresas debido a que, aunque no todas obtienen ayuda, tampoco tienen la negación absoluta; más bien las medianas empresas deberían preocuparse más en incorporarse a cadenas de valor y en buscar la excelencia en resultados de índole productivo en su ramo y en aprovechar esos beneficios que tienen para el entrenamiento de su planta, y así convertirse en grandes empresas en un plazo determinado.

Con respecto a la banca de desarrollo, Nafin en 2009 prestó 240000000000 de pesos, mientras que en 2014 fueron 303000000000 de pesos, es decir, se vio claramente un crecimiento. Sin embargo, cabe resaltar que solo se les brindó la oportunidad de financiamiento a $50 \%$ de las empresas que tenían garantía por parte de Safin, según Banxico (2015).

Entonces, siguen los obstáculos e incógnitas constantes en la actualidad y la problemática viene desde años anteriores, y lo peor es que son para las empresas que cuentan con menor número de trabajadores, que no tienen planes de acción, suficiente antigüedad, entre otras, y lógicamente se ven afectadas y como futuro tienden a desaparecer por la falta de apoyo.

El sistema por parte de la banca para el desarrollo de mipymes es obsoleto en México. Por ello se presentará un comparativo del apoyo por parte de instituciones a empresas que se desarrollan dentro de un país, con la finalidad de observar la diferencia y comprobar efectivamente que en México hace falta una cultura de apoyo a las empresas, sobre todo a las mipymes. A continuación, en la tabla 1 se describen a las empresas con crédito en otros países en comparación con las de México, según Banxico (2015) y la Comisión Económica para América Latina y el Caribe [Cepal] (2015). 


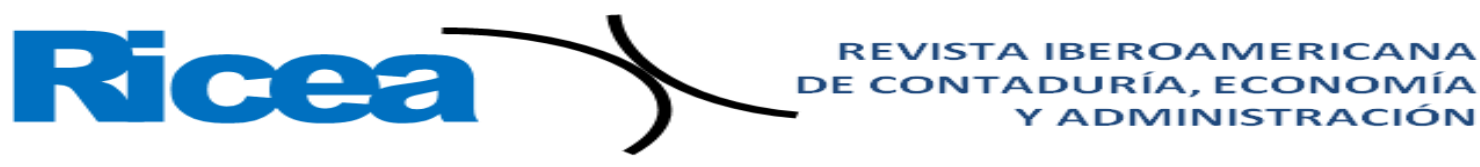

ISSN $=2007-9907$

Tabla 1. Empresas con crédito en otros países y en México

\begin{tabular}{|c|c|c|c|}
\hline \multirow{2}{*}{ País } & $\begin{array}{c}\text { Hasta 100 } \\
\text { empleados }\end{array}$ & $\begin{array}{c}\text { Más de 100 } \\
\text { empleados }\end{array}$ & $\begin{array}{c}\text { Proyecciones del } \\
\text { PIB }\end{array}$ \\
\hline Chile & 78.0 & 81.7 & 3.0 \\
\hline Perú & 63.0 & 92.7 & 4.2 \\
\hline Colombia & 51.3 & 92.2 & 3.6 \\
\hline Brasil & 57.0 & 89.6 & -0.9 \\
\hline Uruguay & 46.5 & 75.2 & 3.0 \\
\hline Argentina & 46.5 & 75.3 & 5.0 \\
\hline Bolivia & 44.9 & 78.6 & -3.5 \\
\hline Promedio & 45.4 & 67.5 & 3.0 \\
\hline Venezuela & 29.5 & 85.4 & 3.0 \\
\hline Honduras & 30.3 & 31.7 & 6.0 \\
\hline México & 29.5 & 54.0 & 10.1 \\
\hline Panamá & 21.0 & $2015)$ \\
\hline
\end{tabular}

Fuente: Elaboración propia con base en Banxico (2015) y Cepal (2015)

México cuenta con un producto interno bruto (PIB) promedio con respecto a otros países, pero el financiamiento a las mipymes es bajo, sobre todo en México como se describió en el cuadro anterior. Por lo que la Corporación Financiera Internacional [IFC] (2013) relaciona estos dilemas con lo siguiente:

1) El riesgo moral. Que el deudor no pague a tiempo,

2) Falta de garantías reales. Reputación usada como garantía,

3) Dificultad de monitoreo. La negligencia de las empresas.

En un escenario tan catastrófico a razón de la falta de confianza que la banca le tiene a las mipymes obviamente el resultado es recíproco: la ausencia de las empresas y el estancamiento del crecimiento económico en México y en diferentes factores externos e internos de la economía.

En definitiva, las mipymes necesitan un modelo alternativo para la obtención de créditos o financiamientos para utilizarlos en algunas de las variables mencionadas. De allí la importancia de la presente investigación. Además de proponer un modelo, se necesita 
entender desde origen el problema, con un análisis del impacto del acuerdo de Basilea III en el otorgamiento de crédito a las mipymes en México.

¿Para qué? Para inferir en las razones por las cuales la banca se comporta de esa manera con las organizaciones que conforman este grupo; descifrar el mercado internacional de las mipymes, y asimilar las regulaciones de la mano de una nueva propuesta con el modelo que se desea expresar para la contribución de una metodología adecuada para el crédito hacia estas empresas en México.

Para Gitman (2012) y Zutter (2012), la definición conceptual del financiamiento se debe entender como la transacción de fondos por parte de los individuos de una sociedad, por parte del estrato empresarial, o bien por el Gobierno, el cual es adquirido para cubrir sus necesidades. Ahora bien, cuando es adquirido algún tipo de financiamiento por parte de la empresa, por poner un ejemplo, es necesario que cuente con una administración financiera para la incorporación de las finanzas, la economía, los presupuestos y la mercadotecnia.

En realidad, las finanzas y la economía siempre son imprescindibles para la empresa, pues de ellas depende la mayoría de las acciones ejecutadas por parte de esta. En la teoría económica, Aristóteles y Platón expusieron diferentes corrientes para la evolución social. Desde la existencia de la humanidad siempre se ha contado con un intercambio de productos para beneficio de todas las partes involucradas.

Mientras que con las doctrinas del realismo y del liberalismo se veían afectadas las sociedades nacionales y las sociedades internacionales por la falta de acuerdos y datos exactos de la vida presente, además de tener una posición enfocada en términos reales a la conciencia trascendental. Aquí también, por otro lado, de la explicación del realismo y del liberalismo, un tema que resulta fundamental para las bases de las teorías de relaciones internacionales y de la economía son corrientes más actuales para el desarrollo de sanas finanzas dentro de la empresa.

Entonces, estas doctrinas, de una manera directa, repercuten en los acuerdos internacionales; acuerdos que los países deben tener para impulsar su crecimiento. Es así como entra en este contexto el Comité de Basilea I, II y III para la fundamentación de las economías fuertes de los países involucrados. Robles (2012) dice que, definitivamente, el financiamiento es necesario para la empresa, además de tener claro que la definición de la empresa, las finanzas mismas y las funciones financieras son aspectos que también se deben considerar. 

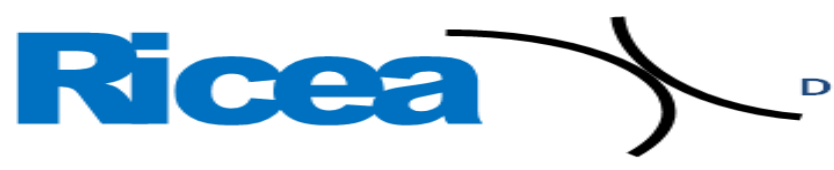

REVISTA IBEROAMERICANA DE CONTADURÍA, ECONOMÍA Y ADMINISTRACIÓN

$15 S N=2007-9907$

En el sentido de que solicitar algún tipo de financiamiento en México actualmente no es fácil, y es que aunque existan regulaciones internacionales no existe la comprensión ni la aplicación de las mismas. Si las empresas no tienen historial crediticio, garantías de algún aval, relaciones internacionales con empresas extranjeras, personal capacitado y con antigüedad en algunos casos, entre otras, la banca múltiple y la de desarrollo olvidan a este sector y se tiene una preferencia a las medianas y grandes. Así, teniendo en cuenta lo dicho hasta este momento, se plantean los siguientes cuestionamientos: ¿Qué sucede en las micro y pequeñas empresas? ¿De dónde obtienen el financiamiento y el crecimiento? ¿Por qué no se le brindan las mismas oportunidades que en los dos estratos restantes?

De no ser por los inversionistas ángeles, el plan de negocios, la aportación de recursos a terceros, en muchos casos las mipymes desaparecerían, siguiendo a Moreno (25 de febrero de 2010). Para otros economistas, por ejemplo, Berger (1996) y Udell (1996), ante esta situación un aspecto interesante a resaltar es que tanto en los países desarrollados como en los países en vías de desarrollo las mipymes han tenido menor acceso al financiamiento externo, además de estar más limitadas en su operación y crecimiento.

Pero esto ha sucedido debido a que las empresas existentes en naciones como Japón, Alemania, Canadá y Estados Unidos han adoptado sistemas de alta productividad, calidad en los procesos y estrategias políticas internas. Por ello es que los financiamientos solicitados por parte de las mipymes son menores cada día.

En este sentido, para una empresa, sobre todo pionera, resulta fundamental la obtención de un financiamiento, para hacer el presupuesto correcto y estar preparados para futuros problemas de acuerdo con las especulaciones del mercado, que se presentan de forma simultánea a su desarrollo. La creación de empresas debe estar detallada por diversos temas de la actualidad, contables y de administración; a su vez, emprender ciertas investigaciones y contar con el correcto endeudamiento, si así se supone que sea.

Ahora bien, deben existir diferentes razones para la creación de la empresa y el motivo de financiación para la misma. En primer lugar, la existencia de una población en donde se pueda ejecutar el proyecto. En segundo, el apoyo de diferentes instituciones para el tema de los financiamientos. En tercero, según indican Sanchís (1999) y Ribeiro (1999), el apoyo de las relaciones comerciales. 
Dicho lo anterior, es importante tener en consideración los altos índices de oportunidad que los créditos y financiamientos ofrecen para elevar la economía de un país, y sí está bien tener cuidado al estrato de las medianas y grandes empresas, pero no olvidarse completamente de las micro y pequeñas empresas en México.

La Organización para la Cooperación y el Desarrollo Económicos [OCDE] (2012) apunta que el canal internacional con mayor relevancia es el financiero o el de endeudamiento. Un aspecto importante es que cada nación debe apoyar a las mipymes y de ahí partir para el crecimiento. Mientras más jóvenes en términos comerciales sean, más considerables y rentables serán en la operación de sus actividades diarias, y evitar el riesgo de una parada repentina o sudden stop, llamada así por economistas, y problemas de financiamiento por "disrupciones" en los mercados de capitales internacionales.

Es decir, consecuentemente con lo anterior, además de un adecuado endeudamiento, también es necesario como empresa estar formulando un plan de acción emergente para considerar todas las posibilidades necesarias en la ejecución de la marca y no generar una parada súbita.

Ahora bien, el término sudden stop es también descrito como el umbral de fondos o recursos repentinos, y que en el peor de los casos pueden llegan a representar problemas de sustentabilidad fiscal (Suárez y Poveda, 2016). Por ello, se van a buscar datos e información que estén relacionados con el tema objetivo y que tal vez puedan ser sometidos a un análisis posterior, como referencia para una nueva investigación.

Para otros economistas como Del Cid (2007), Méndez (2007) y Sandoval (2007) es importante detallar las fuentes de información, las características de la población, las cuales son las unidades de análisis, es decir, a qué se va a enfrentar el investigador, las principales variables objeto de estado de la misma: se debe comenzar por el contenido, lugar y tiempo. 


\section{Método}

\section{Diseño de la investigación}

Para esta investigación la metodología aplicada fue cualitativa y el método deductivo, con el propósito de revisar las principales variables que presenta Basilea III y su incursión en la banca de desarrollo y múltiple del país. Para más tarde revisar los factores y la manera en cómo afecta a la economía la oposición de un crédito o financiamiento a las mipymes y al resto del país.

\section{Elementos de la investigación}

Las fuentes principales fue el estrato empresarial de México; el sector más importante que desarrolla y forma parte de la gran actividad económica de los mexicanos, las mipymes. Apoyada y basada la información en diversas instituciones y aplicado el análisis del acuerdo de Basilea III.

\section{Recolección de datos}

Fuentes citadas de diversos portales oficiales, principalmente el SFM (Amaii, 2017), Banxico (2015), el Comité de Basilea III, el Inegi (2015a, 2015b, 2016a, 2016b), la Cepal (2015) y del Popolo (2016), entre otras.

\section{Indicadores}

Se trata del segmento específico de la población, sin la necesidad que se estudien todos sus elementos, y como característica principal la representación de las mismas características de la población. A continuación, se muestran algunas variables para el entendimiento de un crédito (ver tabla 2). 


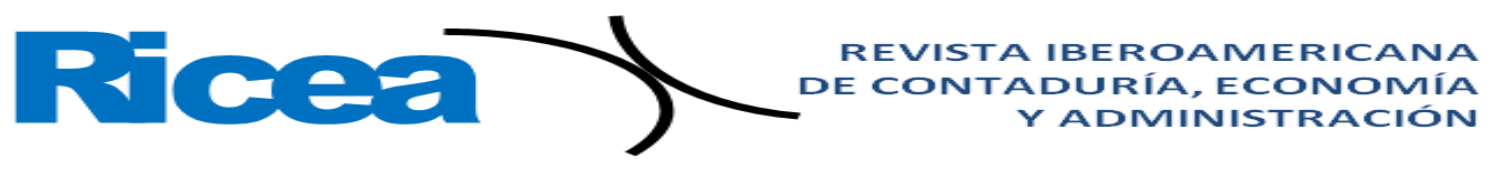

ISSN = $2007-9907$

Tabla 2. Variables de entendimiento de un crédito

\begin{tabular}{|c|c|c|c|c|}
\hline \multicolumn{2}{|c|}{ VARIABLES DE ESTUDIO } & \multicolumn{3}{|c|}{ OPERACIONALIZACIÓN DE LAS VARIABLES } \\
\hline Variables & Indicadores & Concepto & Operación & $\begin{array}{c}\text { Función de la } \\
\text { banca }\end{array}$ \\
\hline $\begin{array}{c}\text { Categorías } \\
\text { sociodemográficas }\end{array}$ & $\begin{array}{l}\text { a) Población } \\
\text { b) Producción } \\
\text { c) Productividad } \\
\text { d) Tecnologías } \\
\text { de la } \\
\text { información y } \\
\text { la } \\
\text { comunicación } \\
\text { (TIC) } \\
\text { e) Investigación } \\
\text { y desarrollo }\end{array}$ & $\begin{array}{l}\text { Cepal (2016): } \\
\text { características } \\
\text { sociales y } \\
\text { demográficas } \\
\text { que determinan } \\
\text { el } \\
\text { comportamiento } \\
\text { con base en } \\
\text { necesidades } \\
\text { específicas de } \\
\text { un segmento. }\end{array}$ & $\begin{array}{l}\text { Estudios y } \\
\text { encuestas de } \\
\text { la población, } \\
\text { producción, } \\
\text { TIC e } \\
\text { investigación } \\
\text { del } \\
\text { desarrollo. }\end{array}$ & $\begin{array}{lr}\text { Hace } & \text { una } \\
\text { investigación } & \text { a } \\
\text { todos } & \text { los } \\
\text { indicadores } & \\
\text { descritos y } & \text { con } \\
\text { base en } & \text { el } \\
\text { resultado otorga el } \\
\text { crédito. Aquí es en } \\
\text { donde } \\
\text { determinan } \\
\text { variables como el } \\
\text { monto, tasa y } \\
\text { plazo del mismo. }\end{array}$ \\
\hline $\begin{array}{l}\text { Situación } \mathrm{t} \\
\text { de las mip }\end{array}$ & $\begin{array}{l}\text { a) Antigüiedad } \\
\text { b) Giro } \\
\text { c) Perfil de } \\
\text { empresarios } \\
\text { d) Distribución } \\
\text { sectorial }\end{array}$ & 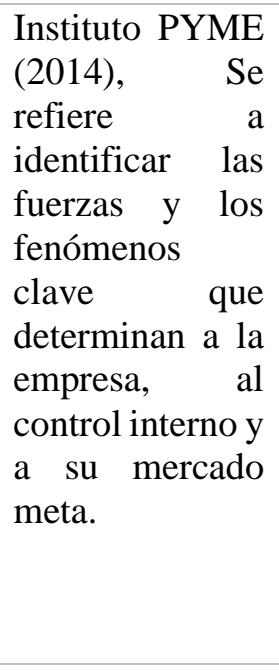 & $\begin{array}{l}\text { Cómo se va a } \\
\text { ejecutar el } \\
\text { modelo con } \\
\text { base en el } \\
\text { resultado de } \\
\text { los } \\
\text { indicadores } \\
\text { de las } \\
\text { variables de } \\
\text { estudio. }\end{array}$ & $\begin{array}{l}\text { En este estudio de } \\
\text { la situación } \\
\text { técnica de la } \\
\text { empresa, la banca } \\
\text { otorga, de acuerdo } \\
\text { con el resultado, la } \\
\text { línea de crédito, la } \\
\text { cuenta que será } \\
\text { depositado y } \\
\text { algunos otros } \\
\text { beneficios, como } \\
\text { tarjetas de crédito } \\
\text { empresariales, por } \\
\text { mencionar tan } \\
\text { solo una. }\end{array}$ \\
\hline $\begin{array}{l}\text { Elementos de las } \\
\text { mipymes }\end{array}$ & $\begin{array}{l}\text { e) PFAE } \\
\text { f) Personas } \\
\text { morales } \\
\text { g) Distribución } \\
\text { según tamaño } \\
\text { h) Ventas e } \\
\text { ingresos }\end{array}$ & $\begin{array}{lr}\text { Dirección } & \\
\text { General de } \\
\text { Industria y de la } \\
\text { Pequeña r y } \\
\text { Mediana } \\
\text { Empresa } \\
\text { (2014): } \\
\text { refiere } \\
\text { identificar qué } \\
\text { ambiente genera } \\
\text { la empresa a } \\
\text { través de su } \\
\text { tamaño, y de } \\
\text { variables } \\
\text { importantes. }\end{array}$ & $\begin{array}{l}\text { En la } \\
\text { investigación } \\
\text { se } \\
\text { desarrollan } \\
\text { respuestas } \\
\text { específicas } \\
\text { de acuerdo } \\
\text { con los } \\
\text { resultados en } \\
\text { los elementos } \\
\text { importantes } \\
\text { de las } \\
\text { mipymes. }\end{array}$ & $\begin{array}{l}\text { En el caso de que } \\
\text { la empresa solicite } \\
\text { a la banca } \\
\text { comercial, esta } \\
\text { determinará si es } \\
\text { óptima la vía, o en } \\
\text { su defecto el } \\
\text { solicitante debe } \\
\text { aplicar a otra } \\
\text { institución. } \\
\text { través de los } \\
\text { elementos de la } \\
\text { mipyme es como } \\
\text { se mide este } \\
\text { indicador. }\end{array}$ \\
\hline
\end{tabular}

Fuente: Elaboración propia con base en Del Popolo (2016), Banxico (2017) y la Dirección

General de Industria y de la Pequeña y Mediana Empresa (2014) 


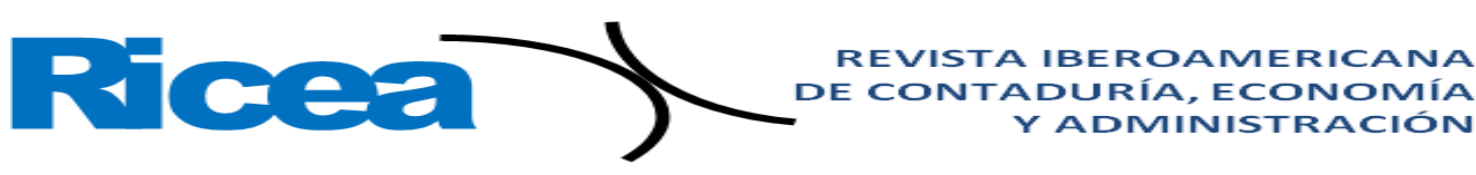

Así es como se describen detalladamente las variables de estudio y la operacionalización de las mismas en la banca de desarrollo, es decir, las entidades que están respaldadas por el Gobierno en México. Por ello, con respecto a las funciones de las entidades, se desarrollará una representación de las actividades y funciones que tienen las instituciones para apoyar y ofrecer a los cuentahabientes de México, en específico a las mipymes, que es el segmento de estudio.

En los mercados financieros deben existir oferentes y demandantes (quien ofrece y quien solicita un crédito respectivamente); en el encuentro de ambos coinciden diferentes variables: las tasas de interés, los montos de los créditos o financiamientos y las líneas de créditos en los diferentes medios (tarjetas de crédito, créditos de nóminas, créditos específicos, crédito refaccionario, crédito de negocios o simples, etcétera); además del negocio de la captación de recursos que los demandantes generan en su historial crediticio, a través de cuentas de cheques, cuentas de ahorro, inversiones a plazo fijo, inversiones en dólares, y diferentes instrumentos para administrar e invertir dinero hacia los bancos en México (los indicadores se pueden ver en la tabla 2, en el apartado de "Situación técnica de la mipymes").

De lo anterior es de donde precisamente la banca obtiene las mayores retribuciones, pues una vez que el público inversionista coloca su dinero a través de los medios descritos, las entidades financieras lo ponen a disposición para el público que necesite crédito y financiamiento mediante altas tasas de interés y con infortunados rendimientos.

Por lo tanto, la banca no utiliza sus recursos propios, más bien los recursos de terceros para seguir emitiendo, generando e invitando para adquirir créditos y financiamientos, así como inversiones para que, su vez, de ahí aplique un aprovechamiento a su manera.

No solo se necesita tener las normas y los estándares a partir de los cuales emitan sus políticas las instituciones, también se debe tratar de la claridad y la transparencia en los procesos de selección para no caer en un riesgo que difícilmente pueda salir la institución y no caer en quebrantos excesivos. 


\section{Resultados}

De estos problemas es de donde se derivan los riesgos de la cartera crediticia en el SFM. Por ejemplo, en la falta de pago o pago tardío por los intereses mensuales que corren en el crédito financiado por el banco al usuario, o a la falta de pago de rendimiento de la inversión del banco hacia el cliente.

Por lo anterior es que existen, asimismo, diferentes teorías para tratar de erradicar dichos problemas, con la posibilidad de incumplimiento de ambas partes o minimizar los márgenes de pérdidas millonarias que debe atender la banca en México. Debido a que de alguna manera todos los acuerdos, las tasas de interés, la eficiente valoración por parte de las agencias de calificación crediticia y los procesos internos de restauración de capital para el objetivo de emitir créditos y financiamientos a mipymes son temas que como país se deben tratar.

Sin duda sería diferente utilizar tales lineamientos y a su vez apoyar al mercado interno en lugar de apoyar a las empresas extranjeras, a la venta de la banca privada y a firmar convenios que, lejos de beneficiar a los mexicanos, logran limitar el crecimiento de la economía.

El crecimiento de las mipymes en México ha sido bueno, sin embargo, no ha sido constante, pues con los cambios económicos, la paridad del dólar, la política de los países vecinos, el precio del petróleo, entre otros factores, se ha visto afectado su desarrollo.

Las empresas mexicanas deben ser más eficientes y preocuparse en tareas de exportación, de adquisición de nuevos productos y del acaparamiento de otros mercados para poder aumentar su crecimiento.

\section{Discusión}

Algunas de las razones principales por las que las mipymes no solicitan un crédito son las que a continuación se presentan: Es caro (53\%), no lo necesitan (34 \%), tienen desconfianza (10\%) y otras razones (3\%). Estos datos son parte de la encuesta realizada por el Inegi (2015a), contando con el apoyo de las organizaciones de este sector.

En la figura 1 se muestran las razones de no solicitar un crédito, a fin de divisar lo descrito. 


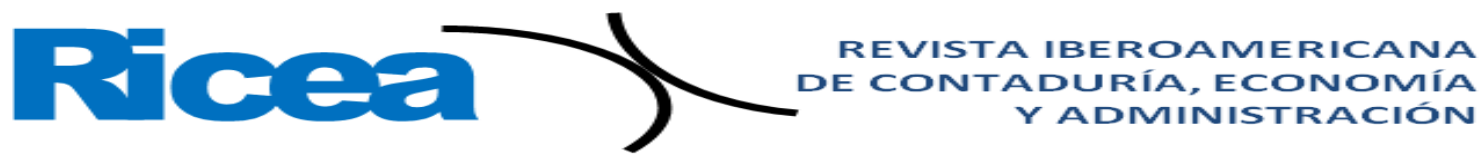

ISSN = $2007-9907$

Figura 1. Razones de no solicitar un crédito en México

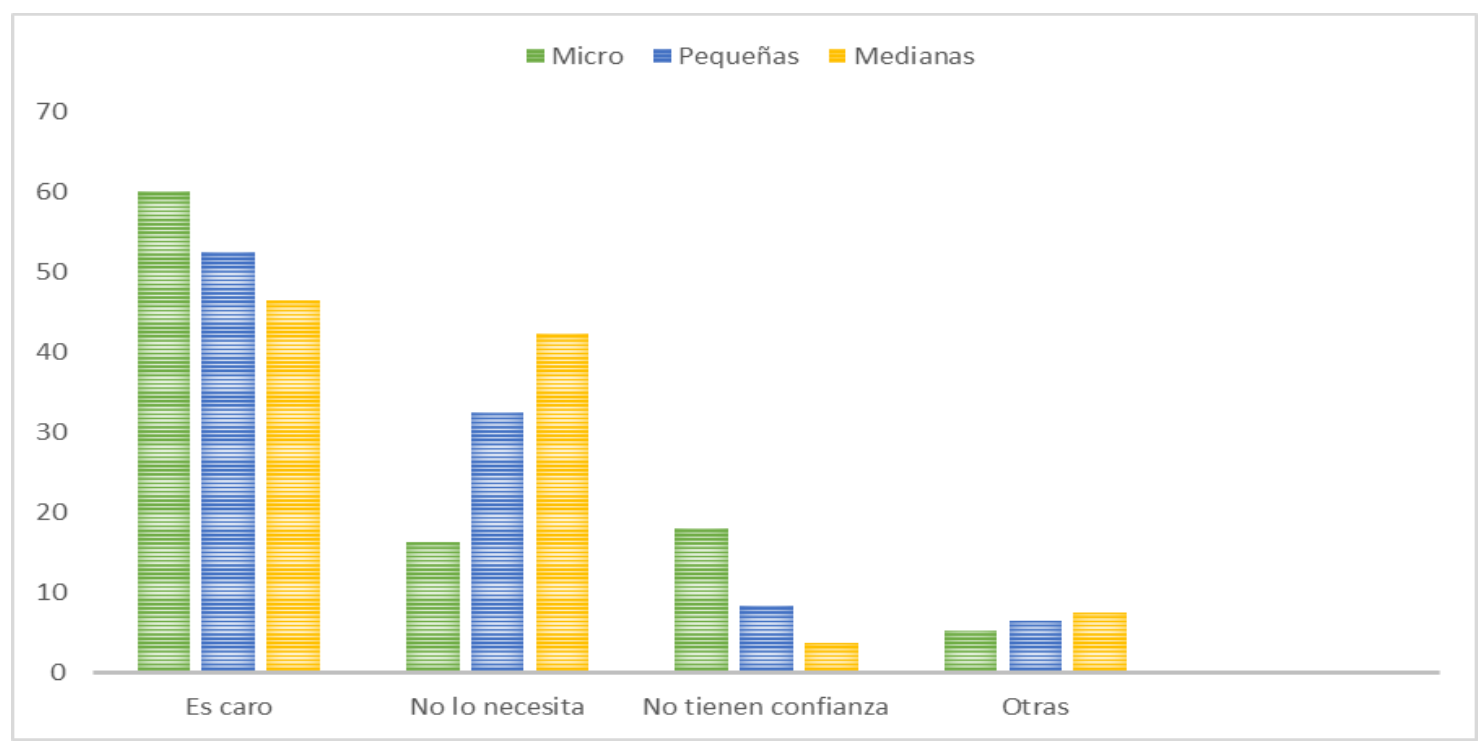

Fuente: Elaboración propia con base en Inegi (2015a)

A partir de la figura anterior se puede asegurar que se debe aplicar un modelo adecuado para la protección de los clientes, en este caso de las mipymes en el sector financiero mexicano. De nada sirve que se cuenten con redes de apoyo al emprendedor o al pequeño empresario si los requisitos se convierten prácticamente traumáticos, pues únicamente los accesos a los créditos son hacia empresas existentes en la cartera de los bancos, las empresas que tienen recomendación y que además la marca sea sujeta a una exhaustiva investigación crediticia.

Hay que recordar que las investigaciones para la obtención de un crédito pueden llevar hasta seis meses para la mipymes, como ya se había comentado. Puesto que se necesitan de la comprobación de los estados de cuenta, de las indagaciones del saldo promedio en las cuentas, de la captación de recursos financieros o de inversiones que tengan las mipymes en el banco solicitante, de la adquisición de créditos a otras entidades de la banca, de la revisión de buró de crédito y de los acuerdos de pago que la empresa tiene con sus proveedores, es decir, cartas de recomendación de estos dos últimos, en la mayoría de los casos. Entonces se debe aplicar un modelo adecuado para la protección de los integrantes de este rubro en el sector financiero mexicano.

De acuerdo con la Comisión Nacional para la Protección y Defensa de los Usuarios de Servicios Financieros [Condusef] (2016), la realidad es que en la práctica esto es lo más común que se suscita, ya que, además de la apariencia que logran tener los empresarios en el marco del financiamiento en México, también, en la mayoría de las veces, ni siquiera tienen 
la noción de generar valor a su marca o empresa, es decir, en la capacitación del personal, en el excesivo endeudamiento en los primeros años de operación, en el financiamiento mal direccionado y, por supuesto, en la falta de conocimiento del lineamiento de su marco de regulación.

\section{Conclusiones}

A partir de lo investigado, se puede ver un panorama claro de que solamente la alianza entre crédito y empresa se logra por el número o tamaño de empresa, ya que no se cuenta con el mismo apoyo en cualquier otro caso. Además de que la regulación del marco de los acuerdos de Basilea (I, II y III) no está funcionando adecuadamente, pues solo se puede deducir que, aunque existan tratados en el país, las micro y pequeñas empresas no cuentan con las mismas oportunidades de desarrollo que las medianas y grandes empresas mexicanas.

$\mathrm{Y}$ es que a lo largo de este texto se han visto algunas cifras de crecimiento por parte de la banca cuando se otorga un crédito, pero aún no es el adecuado, ya que la economía está sostenida casi por toda la actividad de las mipymes. Entonces, de acuerdo con lo hasta aquí expuesto, son muchos más indicadores los que la banca debe medir para que se le tenga confianza a este sector y brindarle oportunidad de crecimiento y expansión. 


\section{Referencias}

Asociación Mexicana de Asesores Independientes de Inversiones [Amaii]. (2017). Organismos del Sistema Financiero Mexicano. México: Asociación Mexicana de Asesores Independientes de Inversiones. Recuperado de http://www.amaii.com.mx/AMAII/Portal/.

Banco de México [Banxico]. (2015). Reporte sobre las condiciones de competencia en el otorgamiento de crédito a las pequeñas y medianas empresas (PYME). México: Banco de México. Recuperado de http://www.banxico.org.mx/publicaciones-ydiscursos/publicaciones/informes-periodicos/reporte-sobre-las-condiciones-decompetencia-en-lo/\%7BB0D52028-C9F4-9410-0DA9-AA76BD9474AB\%7D.pdf.

Beltrán, A. (2006). Los 20 problemas de la pequeña y mediana industria. Sotavento M.B.A., (7), $8-15$.

Recuperado de https://revistas.uexternado.edu.co/index.php/sotavento/article/view/1574.

Berger, A., \& Udell, G. (01 de 03 de 1996). Journal of Business. Obtenido de Relationship lending and lines of credit in small firm finance: https://www.jstor.org/stable/2353332?seq=1\#fndtn-page_scan_tab_contents

Camacho, E. (24 de agosto de 2010). Crédito caro y escaso impide crecer a PYMES. El Universal. Recuperado de https://archivo.eluniversal.com.mx/finanzas/81557.html.

Comisión Económica para América Latina y el Caribe [Cepal]. (2015). Proyecciones de América Latina y el Caribe. Comisión Económica para América Latina y el Caribe. Recuperado de http://www.cepal.org/sites/default/files/pr/files/tabla._proyecciones_pib_america_la tina_y_el_caribe.pdf.

Comisión Nacional para la Protección y Defensa de los Usuarios de Servicios Financieros [Condusef]. (2016). Marco de financiamiento. México: Comisión Nacional para la Protección y Defensa de los Usuarios de Servicios Financieros. Recuperado de http://www.condusef.gob.mx/PDFs/cuadros_comparativos/bancos/cuentas_credito/pymes/empresario_pyme.pdf. Corporación Financiera Internacional [IFC]. (2013). Crédito en Latinoamérica y el Caribe (edición especial). Corporación Financiera Internacional. Recuperado de http://www.ifc.org/wps/wcm/connect/22bb4a0041404758a93fbb3a095bf773/Santia 
go\%2BCroci\%2BUnderstanding\%2BDB\%2BGetting\%2BCredit\%2BIndicator.pdf? MOD=AJPERES.

Del Cid, A., Méndez, R., \& Sandoval, F. (2007). Investigación Fundamentos y Metodología. Mexico: Pearson Educación.

Del Popolo, F. (2016). Características sociodemográficas y socioeconómicas de las personas de edad en América Latina. Santiago, Chile: Comisión Económica para América Latina y el Caribe. Recuperado de http://www.cepal.org/es/publicaciones/7154-caracteristicas-sociodemograficassocioeconomicas-personas-edad-america-latina

Dirección General de Industria y de la Pequeña y Mediana Empresa. (2014). Estadísticas PYME. Evolución e indicadores. España: Recuperado de www.ipyme.org/Publicaciones/ESTADISTICAS-PYME-2015.pdf

Gascón, V. (11 de mayo de 2015). Impide informalidad créditos para pymes. Reforma. Recuperado de https://www.reforma.com/aplicacioneslibre/articulo/default.aspx?id=536716\&md5= 94c00afa4a088ef238c10ddc57b00c80\&ta=0dfdbac11765226904c16cb9ad1b2efe.

Gitman, L. y Zutter, C. (2012). Principios de administración financiera. México: Pearson.

Instituto Nacional de Estadística y Geografía [Inegi]. (2015a). Encuesta nacional sobre productividad y competitividad de las micro, pequeñas y medianas empresas. México: Instituto Nacional de Estadística y Geografía. Recuperado de http://www.inegi.org.mx/est/contenidos/Proyectos/encuestas/establecimientos/otras/ enaproce/default_t.aspx.

Instituto Nacional de Estadística y Geografía [Inegi]. (2015b). Encuesta del desarrollo de establecimientos. México: Instituto Nacional de Estadística y Geografía. Recuperado de

http://www.inegi.org.mx/est/contenidos/Proyectos/encuestas/establecimientos/otras/ enaproce/default_t.aspx.

Instituto Nacional de Estadística y Geografía [Inegi]. (2016a). Productividad. México: México: Instituto Nacional de Estadística y Geografía. Recuperado de http://www.inegi.org.mx/saladeprensa/boletines/2016/especiales/especiales2016_07 _02.pdf. 
Instituto Nacional de Estadística y Geografía [Inegi]. (2016b). Esperanza de vida de la PYME. México: Instituto Nacional de Estadística y Geografía. Recuperado de http://www.inegi.org.mx/inegi/contenidos/Investigacion/Experimentales/esperanza/ default.aspx

Instituto Nacional del Emprendedor [Inadem]. (2016). CDMX: Inadem. Distribución de la bolsa correspondiente a la convocatoria 1.2 productividad económica regional. México: Instituto Nacional del Emprendedor. Recuperado de https://www.inadem.gob.mx/fne/resultados_2016/categoria_uno/conv_1_2.pdf.

Moreno, T. (25 de febrero de 2010). Los 7 financiamientos para Pymes. Expansión. Recuperado de https://expansion.mx/emprendedores/2010/02/25/7-financiamientospara-pymes.

Nacional Financiera [Nafin]. (2016). Alianza PYME. Programa en beneficio de las empresas mexicanas. México: Nacional Financiera. Recuperado de http://www.nafin.com.mx/portalnf/content/sobre-nafinsa/sala-deprensa/boletin_039_14.html.

Organización para la Cooperación y el Desarrollo Económicos [OCDE]. (2012). Perspectivas económicas de América Latina 2013, Políticas de Pymes para el cambio estructural. Organización para la Cooperación y el Desarrollo Económicos. Recuperado de https://books.google.com.mx/books?id=lyCj0Ju5iN4C\&pg=PA29\&dq=pymes+end eudamiento\&hl=es-

419\&sa=X\&ved=0ahUKEwiw6dzk2KvOAhWF4iYKHe9WCVk.

Robles, C. (2012). Fundamentos de administración financiera. México: Red Tercer Milenio. Sanchís, J. y Ribeiro, D. (1999). Creación y dirección de pymes. Madrid, España: Díaz de Santos.

Sistema Único de Gestión Empresarial [SUGE]. (2016). Desarrollo económico. Estado de México, México: Sistema Único de Gestión Empresarial. Recuperado de http://desarrolloeconomico.edomex.gob.mx/suge.

Suárez, L. y Poveda, M. (2016). Sudden Stops y la crisis argentina. Revista de la Universidad de Buenos Aires. Recuperado de www.derecho.uba.ar/publicaciones/rev_juridica/. 